\title{
Combinación de alta cizalla y ultrasonido para la obtención de nanopartículas de carbonato de calcio a partir de cáscara de huevo
}

\author{
Luz M. Gómez-Alvarez¹, Freimar Segura-Sánchez² y José E. Zapata ${ }^{*}$ \\ (1) Facultad de Ciencias Farmacéuticas y Alimentarias. Grupo de Nutrición y Tecnología de Alimentos. Universidad de \\ Antioquia, Medellín, Colombia (correo-e: luz.gomez6@udea.edu.co; edgar.zapata@udea.edu.co) \\ (2) Facultad de Ciencias Farmacéuticas y Alimentarias. Grupo Biopolimer. Universidad de Antioquia, Medellín, Colombia \\ (correo-e: freimar.segura@udea.edu.co) \\ * Autor a quien debe ser dirigida la correspondencia.
}

Recibido Jun. 20, 2021; Aceptado Ago. 17, 2021; Versión final Sept. 27, 2021, Publicado Feb. 2022

\begin{abstract}
Resumen
El objetivo de este estudio fue evaluar el efecto combinado de la dispersión de alta cizalla y ultrasonido de alta intensidad sobre las características de nanopartículas (NPs) de carbonato de calcio $\left(\mathrm{CaCO}_{3}\right)$ de cáscara de huevo de gallina (Gallus gallus domesticus). Se separaron las membranas intersticiales y se caracterizaron las cáscaras: el tamaño de partícula, el potencial zeta, morfología por microscopía, difracción de rayos $X$ y área superficial. Los resultados muestran un tamaño de $572.51 \mathrm{~nm}$, un potencial zeta de -14.9 , y escalado de $281.34 \mathrm{~nm}$ y $-22.4 \mathrm{mV}$ respectivamente. La microscopía reveló nanopartículas de 45 a $500 \mathrm{~nm}$, cristales de 10 a $60 \mathrm{~nm}$ y rugosidad en la superficie. El contenido de calcita fue de $98.7 \%$ y el área superficial fue de 11.13 $\mathrm{m}^{2} / \mathrm{g}$. Se concluye que mediante dispersión a alta cizalla y ultrasonido se pueden obtener nanopartículas de carbonato de calcio con características similares a métodos convencionales.
\end{abstract}

Palabras clave: cáscara de huevo; dispersión de alta cizalla; sonofragmentación; $\mathrm{CaCO}_{3}$; nanopartículas

\section{Combination of high shear and ultrasound to obtain calcium carbonate nanoparticles from eggshells}

\begin{abstract}
The main objective of this research study was to assess the combined effects of high shear dispersion and high-intensity ultrasound on the characteristics of calcium carbonate $\left(\mathrm{CaCO}_{3}\right)$ nanoparticles (NPs) obtained from chicken (Gallus gallus domesticus) eggshells. Interstitial membranes were separated and eggshells were characterized: particle size, zeta potential, morphology by microscopy, X-ray diffraction, and surface area. The results showed a size of $572.51 \mathrm{~nm}$, a zeta potential of -14.9 , and scaling of $281.34 \mathrm{~nm}$ and $-22.4 \mathrm{mV}$ respectively. Microscopy revealed nanoparticles of 45 to $500 \mathrm{~nm}$, crystals of 10 to $60 \mathrm{~nm}$, and surface roughness. Calcite content was equal to $98.7 \%$ and the surface area was $11.13 \mathrm{~m}^{2} / \mathrm{g}$. It is concluded that high shear dispersion and ultrasound of chicken eggshells generates calcium carbonate nanoparticles that have characteristics similar to nanoparticles obtained by conventional methods.
\end{abstract}

Keywords: eggshell; high shear dispersion; sonofragmentation; $\mathrm{CaCO}_{3}$; nanoparticles 


\section{INTRODUCCIÓN}

La reutilización de los residuos es una de las prioridades para el logro del desarrollo sostenible a nivel global (Arabhosseini, 2018). En este contexto, la cáscara de huevo de gallina representa uno de los más abundantes residuos generados por la industria agroalimentaria y sigue siendo dispuesta sin pretratamiento alguno (De Angelis et al., 2017). Según datos de la FAO, China es el mayor productor de huevos en el mundo (40\%), seguido de Estados Unidos (7\%) y la India (6\%); se estima que cerca de 7 millones de toneladas de desechos de cáscara de huevo se descartan anualmente en el mundo (Li et al., 2020). Esta elevada cantidad de residuos despierta interés en la comunidad científica y es por esto que, en los últimos años se han realizado grandes esfuerzos para transformar los desechos de cáscara de huevo en productos de valor agregado (Ding et al., 2020).

La cáscara de huevo es un biomaterial con una estructura especial, conformada principalmente por una fase mineral y una red de fibras proteicas que corresponden a las membranas intersticiales. Su composición química indica que contiene aproximadamente $95 \%$ de carbonato de calcio $\left(\mathrm{CaCO}_{3}\right)$ en forma de calcita, $3 \%$ de material orgánico o matriz proteica que da estructura a los cristales de $\mathrm{CaCO}_{3}$; los componentes residuales corresponden a $1 \%$ de carbonato de magnesio y $1 \%$ de fosfato de calcio, además de algunos elementos traza como Na, K, Zn, Mn, Fe y Cu (Baláž, 2018). La cáscara de huevo se usa para diversos fines, desde procesos de baja inversión para obtener fertilizantes y piensos para animales hasta la transformación del material para el consumo humano (Hess et al., 2018). El campo de aplicación más grande es la utilización como fuente de calcio para la preparación de biocerámicas (hidroxiapatita y fosfato tricálcico) en aplicaciones biomédicas, materiales compuestos y semiconductores, agentes para la administración de fármacos, agente de deshalogenación, absorbentes para la eliminación y recuperación de cobre (Mittal et al., 2016), pigmentos de recubrimiento para papel (Hassan et al., 2013), adsorción de metales pesados y colorantes orgánicos (Mittal et al., 2016); como fuente potencial de bio-rellenos para mejorar las propiedades de los nanocompuestos poliméricos y como fuente de materias primas útiles para producir nanomateriales (Huang et al., 2020). En general, se ha utilizado en plásticos, pinturas, papel, tintas, alimentos e industria farmacéutica.

La nanotecnología ha demostrado que las estructuras en esta escala mejoran sus propiedades funcionales, es por esto que se han usado nanopartículas (NPs) de cáscara de huevo como agente de nucleación en material compuesto derivado de almidón de maíz, para aplicación en empaques de alimentos mejorando sus propiedades físicas y mecánicas (Hassan et al., 2013). Es así, como los nanomateriales (ENM), denominados estructuras de ingeniería con al menos una dimensión de $100 \mathrm{~nm}$, han incursionado en la industria alimentaria durante los últimos años y en este campo se ha indicado que la fortificación de alimentos con ingredientes en escala nano $(<1000 \mathrm{~nm})$, mejoran la eficiencia en la absorción y biodisponibilidad a través de la reducción del tamaño de partícula permitiendo que minerales como el calcio se absorban más fácilmente en el tracto gastrointestinal (Erfanian et al., 2014). Con pocas excepciones, se incluyen principalmente estudios realizados con sistemas de administración ENM preparados a partir de ingredientes de grado alimentario, materiales vegetales molidos y minerales con distribuciones de tamaño de partícula dentro del rango de hasta $300 \mathrm{~nm}$.

La obtención de ENM se puede generar a partir de dos enfoques: el enfoque de abajo hacia arriba o Bottom up, es decir; a partir de moléculas individuales, mediante reacciones químicas o mediante el autoensamblaje de componentes individuales lo cual resulta en la creación de cápsulas, fibras o tubos que se pueden usar como sistemas de administración para moléculas más pequeñas, por ejemplo, compuestos bioactivos o aromáticos (Baláž, 2018). Mientras que los procesos de preparación de ENM basados en la fragmentación de estructuras más grandes en estructuras más pequeñas, generalmente mediante la entrada de energía mecánica o térmica, por ejemplo, molienda, homogeneización a alta presión, dispersión a alta cizalla y ultrasonido; se conocen como el enfoque de arriba hacia abajo o Top Down (Pohshna et al., 2020). El material de partida puede consistir, por ejemplo: en materiales vegetales, oligoelementos o minerales (Baláž, 2018).

La cáscara de huevo posee características fisicoquímicas que favorecen su transformación en la nano escala a través de procesos top down, sin embargo; para que sea más eficiente se requiere la combinación de técnicas que permitan la reducción del tamaño de partícula; como la dispersión de alta cizalla y ultrasonido, esta última como una herramienta sonoquímica que permite la obtención de nanopartículas más pequeñas, dispersas y con mayor área superficial (Hassan et al., 2013). La cizalladura es una de las fuerzas utilizadas en la reducción de tamaño de partículas, realizada a través de sistemas de alto corte como el efectuado en un homogeneizador rotor-estator, que gracias a la disipación de energía localizada y a las velocidades de corte intensas generan el proceso de dispersión y reducción de tamaño. Mientras que la sonicación a altas intensidades produce ondas de sonido que se propagan al medio líquido y dan como resultado ciclos alternos de alta presión (compresión) y baja presión (expansión), con velocidades que dependen de la frecuencia (Benavides-Guerrero et al., 2020). Durante el ciclo de baja presión, las ondas ultrasónicas de alta intensidad crean pequeñas burbujas de vacío en el líquido, cuando las burbujas alcanzan un volumen en el que ya no pueden absorber energía, colapsan violentamente (implosionan) durante un ciclo de alta presión en un fenómeno denominado cavitación a través del cual se pueden obtener NPs de $\mathrm{CaCO}_{3}$ (Hassan et al., 2013). 
Valorizar desechos como las cáscaras de huevo, empleándolos como una fuente de calcio alternativa trae ventajas como: reducir el impacto en las reservas naturales de piedra caliza extraída de fuentes no renovables; disminuir el impacto ambiental y el riesgo microbiológico que representa el contenido orgánico de este material; reducir los costos de eliminación de estos desechos, y por último desarrollar productos con alto valor aprovechando su componente principal $\left(\mathrm{CaCO}_{3}\right)$ como ingrediente en alimentos. El objetivo principal de esta investigación es obtener nanopartículas de carbonato de calcio mediante un proceso combinado de dispersión de alta cizalla y ultrasonido de alta intensidad, a partir de la cáscara de huevo de gallina rojo AA (Gallus gallus domesticus) para aplicación en la industria de alimentos, con el fin de lograr una mayor biodisponibilidad de este mineral en el organismo humano.

\section{METODOLOGÍA}

La metodología presenta varias subsecciones, inicialmente se describe la separación de las membranas intersticiales y la caracterización de la cáscara de huevo, luego la preparación de las micropartículas de cáscara de huevo para la reducción de tamaño de partícula como una etapa previa, posteriormente la obtención y caracterización de las NPs de $\mathrm{CaCO}_{3}$, el escalado del proceso de sonofragmentación y por último se estableció el análisis estadístico.

\section{Pretratamiento de la cáscara de huevo}

Los huevos de gallina rojo AA (Gallus gallus domesticus), fueron obtenidos en un mercado local de Medellín, Colombia. Se les separaron las cascaras, las cuales se lavaron varias veces con agua y se secaron a $80^{\circ} \mathrm{C}$ durante 2 horas. Se les retiraron las membranas intersticiales mediante un proceso de "Separación por diferencia de densidades" de acuerdo al método de MacNeil, J., (2001) con algunas modificaciones. Esto se da gracias a la turbulencia creada al interior del recipiente que contiene las cáscaras en fase acuosa, mediante un agitador de brazo a velocidad lenta $(140 \mathrm{rpm})$ para lograr la flotabilidad de las membranas intersticiales y la sedimentación de las partículas de cáscara de huevo. Se realizaron 3 ensayos por triplicado con $300 \mathrm{~g}$ de cáscara de huevo en $1200 \mathrm{~mL}$ de solución y se determinó el rendimiento en peso seco de las cáscaras sin membrana en cada ensayo. Ensayo $\mathrm{N}^{\circ} 1$ : agua destilada $(A D)$. Ensayo $\mathrm{N}^{\circ} 2$ : agua destilada y ácido acético al $5 \%(\mathrm{AD} / \mathrm{AC})$ a $20^{\circ} \mathrm{C}$. Ensayo $\mathrm{N}^{\circ} 3$ : agua destilada a $80^{\circ} \mathrm{C}\left(\mathrm{AD} / 80^{\circ} \mathrm{C}\right)$.

\section{Caracterización de la cáscara de huevo}

A las cáscaras de huevo se les determinó mediante análisis proximal el contenido de humedad, grasa, proteína y cenizas de acuerdo con los métodos de la AOAC (AOAC, 2005). Adicionalmente, se realizaron pruebas de calidad microbiológica (Codex Stan CAC/RCP 15-2007). Los análisis se hicieron por triplicado para las cáscaras de huevo con y sin membranas.

\section{Preparación de partículas de $\mathrm{CaCO}_{3}$ de cáscara de huevo}

Se evaluaron varios métodos de reducción el tamaño de partícula hasta la escala micrométrica, con el fin de seleccionar el más eficiente. Para tal fin se usó un molino de bolas cerámico (DENVER, China), un molino de bolas centrífugo S-1000 (RETSCH, Alemania), un molino de bolas planetario (FRITSCH, Alemania) y un dispersor de alta cizalla - ultraturrax OV5 (VELP Scientífica, EE.UU.). El tamaño de partículas se clasificó por granulometría con un agitador de tamices ROTAP RX29 (Tyler) y un juego de tamices ASTM E-11 (Tyler).

\section{Obtención de $\mathrm{Nano}-\mathrm{CaCO}_{3}$ de cáscara de huevo}

Para la obtención de $\mathrm{CaCO}_{3}$ en la escala nanométrica se combinaron dos métodos, aplicando en cada uno un diseño experimental con el objetivo de determinar las condiciones óptimas para su aplicación. En la primera fase se usó dispersión de alta cizalla y en la segunda sonofragmentación por ultrasonido. Este último ha sido usado con éxito para la obtención de nano partículas de diferentes materiales, gracias a las altas temperaturas y presiones, así como a las muy altas ratas de enfriamiento que se presentan durante la formación y colapso de las burbujas causadas por la irradiación ultrasónica (Tarig et al., 2013).

En la primera fase se preparó el sistema con $10 \mathrm{~g}$ de cáscara de huevo triturada en $100 \mathrm{~mL}$ de solución agua destilada/dispersante y se procesó en el dispersor de alta cizalla - ultraturrax OV5 (VELP Scientífica, EE. UU.). Se planteó un diseño experimental de superficie respuesta central compuesto, con 21 corridas experimentales, tomando como factores el tiempo (30 - $60 \mathrm{~min})$ y la concentración de dispersante $(0.5 \%$ $1 \%$ ) y como variable respuesta el tamaño promedio de partícula (TP) (nm) y el índice de polidispersidad (IPD). Los rangos establecidos para los factores tiempo y dispersante se definieron a través de ensayos preliminares. El tamaño de partícula de carga $(425 \mu \mathrm{m})$ y la velocidad de rotación $(22000 \mathrm{rpm})$ fueron variables fijas. Para el análisis se utilizó el software Design-Expert® 10.0.6 (Stat-Ease, EE. UU.). 
En la segunda fase, el $\mathrm{CaCO}_{3}$ previamente dispersado en el homogeneizador ultraturrax, fue sometido a un proceso de sonofragmentación por ultrasonido en un equipo Vibra Cell VCX 500 (SONICS, EE. UU.). Se preparó el sistema, similar al contenido de carga usado por Baláž, M., (2018); con $3.5 \mathrm{~g}$ de muestra en 700 $\mathrm{ml}$ de solución (agua destilada/etanol). Para definir las condiciones de operación del sonofragmentador se aplicó un diseño experimental de superficie de respuesta central compuesto, con 13 corridas experimentales, utilizando como factores el \% de amplitud (36\% - 64\%) y la concentración de solvente (14\% - 56\%) y como variables respuesta: el tamaño promedio de partícula (TP) (nm), el índice de polidispersidad (IPD) y el potencial zeta (PZ). Para el análisis se utilizó el software Design-Expert® 10.0.6 (Stat-Ease, EE. UU.). Para la determinación de TP e IPD se utilizó un equipo Zetasizer Nano ZS90 (Malvern Instruments, Reino Unido). La amplitud fue tomada como un factor importante en la investigación, puesto que, en ensayos preliminares, los incrementos de frecuencia en el rango de alta frecuencia $(20480$ a $20500 \mathrm{~Hz})$, se evidenció una disminución en la generación de burbujas, por tanto, fue necesario aumentar la intensidad de la radiación, por medio del incremento en la amplitud de la onda.

\section{Caracterización de las NPs de carbonato de calcio}

A las nanopartículas de $\mathrm{CaCO}_{3}$ se les analizó TP, IPD y PZ; características morfológicas y composición elemental mediante técnicas de microscopia; cristalinidad y fase del carbonato; y por último área superficial específica.

\section{Tamaño de partícula e índice de polidispersidad}

Se usó el método de dispersión de luz dinámica (DLS por sus siglas en inglés). Se dispersó $0.1 \mathrm{~g}$ de NPs en $10 \mathrm{~mL}$ de etanol, se mezcló bien y se colocó $1 \mathrm{~mL}$ de la suspensión en la celda para analizar por triplicado TP e IPD en Zetasizer Nano ZS90 (Malvern Instruments, Reino Unido) a $25^{\circ} \mathrm{C}$ y una longitud de onda de $633 \mathrm{~nm}$ (Jeong et al., 2013).

\section{Potencial zeta}

La medición de PZ se realizó en Zetasizer Nano ZS90 (Malvern Instruments, Reino Unido) a $25^{\circ} \mathrm{C}$ y un ángulo de $15^{\circ}$. Para esto se diluyó $0.1 \mathrm{~g}$ de muestra en $10 \mathrm{~mL}$ de agua desionizada y se inyectó $1 \mathrm{~mL}$ de la muestra diluida en la celda de flujo, verificando la ausencia de burbujas de aire y que no se sobrepase el nivel establecido en la celda. Todas las mediciones fueron realizadas por triplicado (Huang et al., 2020).

\section{Análisis de microscopías electrónicas}

Las características morfológicas de superficie y de tamaño de las partículas se investigaron usando microscopía electrónica de barrido y el análisis de composición elemental de la superficie se llevó a cabo utilizando un detector de espectroscopía de rayos $X$ de dispersión de energía (EDS por sus siglas en inglés) que analiza los rayos $X$ generados como producto de la interacción del haz de electrones de un microscopio electrónico de barrido con material sometido a análisis para la identificación y cuantificación de rayos X. Para tal fin, cada muestra se extendió sobre la superficie de una cinta de carbono de doble pegamento, después de la pulverización con oro durante $120 \mathrm{~s}$ (Nasrollahzadeh et al., 2016) y fueron medidas en un microscopio SEM-EDS CX-200 TM (Coxem, Korea).

Las formas y tamaños de los cristales de las nanopartículas también se determinaron utilizando un microscopio electrónico de transmisión (TEM) JEM-2010 (JEOL, Japón), con un voltaje de aceleración de 100 $\mathrm{KV}$. La suspensión de NPs de $\mathrm{CaCO}_{3}$ se preparó dispersando las partículas en una solución de etanol absoluto mediante ultrasonidos. Luego, se colocaron 1-2 gotas de la suspensión diluida en rejillas recubiertas con película Formvar y se dejó secar a temperatura ambiente antes del análisis. El análisis de microscopía de fuerza atómica (AFM), se realizó en un microscopio Core-AFM (Nanosurf, Suiza) calculando las fuerzas entre una sonda y la superficie a una distancia muy corta (Jeyakumar et al., 2018).

\section{Difracción de rayos $X$}

Para la caracterización del patrón de cristalinidad del carbonato de calcio obtenido de la cáscara de huevo mediante el proceso de sonofragmentación en ultrasonido de alta intensidad, se utilizó el patrón de difracción de rayos $\mathrm{X}$ que permite investigar las estructuras de fase de las partículas de $\mathrm{CaCO}_{3}$ preparadas. La pureza y cristalinidad de las nanopartículas de $\mathrm{CaCO}_{3}$ se determinaron mediante un difractómetro Rayos $\mathrm{X}$ (DRX) XPert PANalytical Empyrean Serie II, Modelo 2012, goniómetro Omega/2 theta (Malvern Panalytical, Reino Unido), operado a $40 \mathrm{kV}$ y $30 \mathrm{~mA}$ con un ángulo de exploración (20: 5- 80), con un tamaño de paso $0.026^{\circ}$. La semicuantificación se realizó usando el software High Score Plus mediante el método Rietveld y la base de datos: ICSD FIZ Karlsruhe 2012-1 (Minić et al., 2012). 


\section{Área de superficie específica}

El área de superficie específica se determinó mediante el método de isotermas de adsorción de nitrógeno a baja temperatura utilizando un analizador de área de superficie y poro de ASAP 2020 (Micrometics, Brasil). Los valores se calcularon utilizando la teoría BET (Brunauer, Emmett y Teller) (Nasrollahzadeh et al., 2016).

\section{Análisis Estadístico}

El modelo desarrollado y la significancia estadística de los coeficientes de regresión fueron probados mediante análisis de varianza (ANOVA). La significancia de los coeficientes estimados en el modelo se probó con el estadístico $\mathrm{F}$ (valor-P) con un nivel de confianza del 95\%.

\section{Escalado del proceso de sonofragmentación}

Posterior a la optimización del modelo de fragmentación de partículas de $\mathrm{CaCO}_{3}$, mediante la aplicación de ultrasonido de alta intensidad en escala laboratorio; se efectuó el escalado de la sonofragmentación a un equipo ultrasonido industrial ISP-3000 (SONOMECHANICS, EE.UU.), el cual fue operado en ciclos de 20 minutos durante un tiempo de 2 horas con 10 minutos de descanso entre cada ciclo, temperatura $\left(27 \mathrm{a} 36^{\circ} \mathrm{C}\right)$, amplitud: $40 \%$, frecuencia ( 20480 a $20500 \mathrm{~Hz}$ ). Se sonicaron en cada prueba $20 \mathrm{~L}$ de solución con $5 \%$ de carga de $\mathrm{CaCO}_{3}$, en flujo continuo de $1.5 \mathrm{~L} / \mathrm{min}$. La muestra se mantuvo en constante agitación a $200 \mathrm{rpm} / \mathrm{min}$. Estos ensayos fueron realizados por triplicado, mientras que la caracterización de las muestras obtenidas en el escalado se determinó a través de la distribución de tamaño de partícula, índice de polidispersidad y potencial zeta. Así mismo, se comprobó la morfología mediante DRX y el tamaño por microscopia electrónica de transmisión (TEM).

\section{RESULTADOS Y DISCUSIÓN}

Los resultados de los ensayos de separación de membranas intersticiales por diferencia de densidades mostraron un rendimiento en masa de $93.47 \%, 81.95 \%$ y $93.38 \%$ para los ensayos $A D, A D / A C$ y $A D / 80^{\circ} \mathrm{C}$, respectivamente. Por lo que se seleccionó el método $A D$, para separar las membranas de las cáscaras. Este resultado es muy importante porque permite seleccionar el método más económico (no hay que calentar), ecológico (no hay que agregar ácidos u otros reactivos contaminantes) y muy probablemente permite realizar con mayor facilidad el escalado del proceso.

En la tabla 1 se muestra la composición química proximal de cáscaras de huevo, estos resultados coinciden con Waheed et al., (2019) quienes reportaron $33.13 \%$ y $34.12 \%$ de $\mathrm{Ca}, 5 \%$ de proteína y $93 \%$ de ceniza. Adicionalmente, los análisis microbiológicos reportaron ausencia de patógenos como Salmonella spp en cáscaras con y sin membrana, mientras que, en los recuentos de microorganismos indicadores como bacterias aerobias mesófilas, mohos, levaduras y coliformes totales y fecales se evidenció mayor crecimiento en las cáscaras con membranas intersticiales (datos no mostrados).

Tabla 1: Composición proximal de las cáscaras de huevo

\begin{tabular}{|c|c|c|}
\hline Composición & Cáscara con membrana & Cáscara sin membrana \\
\hline Humedad g/100 g & 0.87 & 0.82 \\
\hline Proteína g/100 g & 5.75 & 4.37 \\
\hline Grasa g/100 g & 7.13 & 6.21 \\
\hline Cenizas g/100 g & 82.51 & 81.26 \\
\hline Ca \% & 32.8 & 33.9 \\
\hline
\end{tabular}

\section{Obtención de partículas de $\mathrm{CaCO}_{3}$}

En la etapa preliminar de reducción de tamaño de partícula de $\mathrm{CaCO}_{3}$ mediante procesos de molienda y dispersión de alta cizalla como pretratamiento para la sonofragmentación, se logró determinar el proceso de dispersión mecánico más eficiente, en el cual el sistema de alta cizalla mediante rotor - estator, mostró un mejor desempeño en la dispersión de las partículas como se puede apreciar en la tabla 2. Esto favorece el rendimiento del material, con una disminución sustancial del tamaño de partícula y menor tiempo de proceso, comparado con el molino planetario, el cual ha sido reportado entre los más aplicados en procesos de molienda de cáscara de huevo a pesar del riesgo de contaminación por el desgaste de las bolas y la difícil recuperación del material adherido a los medios de molturación (Baláž, 2018). Estos resultados demuestran que el mecanismo de alta cizalla favorece la ruptura de partículas de cáscara de huevo debido a la disipación de energía localizada y las velocidades de corte intensas que genera el proceso de dispersión. Adicionalmente, un tamaño de párticula menor en etapas posteriores de reducción de tamaño, dará lugar a procesos más eficientes y permitirá una mayor homogeneidad en el proceso de sonofragmentación (Shirsath et al., 2017). 
Tabla 2: Mecanismos de reducción de tamaño de partícula de $\mathrm{CaCO}_{3}$

\begin{tabular}{|l|c|c|c|}
\hline \multicolumn{1}{|c|}{ Mecanismo } & Tiempo $(\mathrm{h})$ & Tamaño promedio de Partícula $(\mu \mathrm{m})$ & $\% \mathrm{CaCO}_{3}$ en polvo \\
\hline Molino cerámico de bolas & 1 & 45 & 11.81 \\
\hline Molino centrífugo de bolas & 1 & 45 & 15 \\
\hline Molino planetario de bolas & 10 & 8.52 & 92 \\
\hline Dispersión de Alta Cizalla & 1 & 1.5 & 89 \\
\hline
\end{tabular}

\section{Efecto del tiempo y el dispersante sobre TP}

En la tabla 3 se muestra el ANOVA para tamaño de partícula durante el proceso de dispersión a alta cizalla, el cual contiene la significancia estadística del modelo, valor-P de cada factor o interacción, el $R^{2}, R^{2}$-Ajustado y la carencia de ajuste. El análisis de varianza arrojó un modelo cúbico, con una carencia de ajuste no significativa. La variable con mayor significancia fue tiempo, indicando que éste tiene un mayor efecto sobre la reducción de tamaño de partícula. Esto posiblemente se debe a que a mayor tiempo de dispersión se logra mayor pulverización en el medio, sin embargo, cuando se generan partículas muy finas pueden alcanzar un valor límite de tamaño porque cada vez son más difíciles de romper a través de las fuerzas de corte del sistema de cizalla aplicado y posiblemente esté relacionado con que las partículas se vuelven elásticas cuando el tamaño de partículas está en el rango de 500 a $800 \mathrm{~nm}$, como lo informaron Strobel et al., (2017). Adicionalmente, esta alta distribución de partículas posiblemente afecte la sonofragmentación posterior, cuando se aplica ultrasonido de alta intensidad.

Tabla 3: Análisis de varianza TP

\begin{tabular}{|l|c|}
\hline \multicolumn{1}{|c|}{ Fuente $(\mathrm{Xi})$} & Valor - $\mathrm{P}$ \\
\hline Modelo & $<0.0001$ \\
\hline $\mathrm{A}$-Tiempo & $<0.0001$ \\
\hline $\mathrm{B}$-Dispersante & 0.0024 \\
\hline $\mathrm{AB}$ & $<0.0001$ \\
\hline $\mathrm{A}^{2}$ & $<0.0001$ \\
\hline $\mathrm{B}^{2}$ & 0.2564 \\
\hline $\mathrm{A}^{2} \mathrm{~B}$ & 0.0472 \\
\hline $\mathrm{AB}^{2}$ & 0.0003 \\
\hline Carencia de Ajuste & 0.1055 \\
\hline $\mathrm{R}^{2}$ & 0.9177 \\
\hline $\mathrm{R}^{2}$-Ajustado & 0.8733 \\
\hline
\end{tabular}

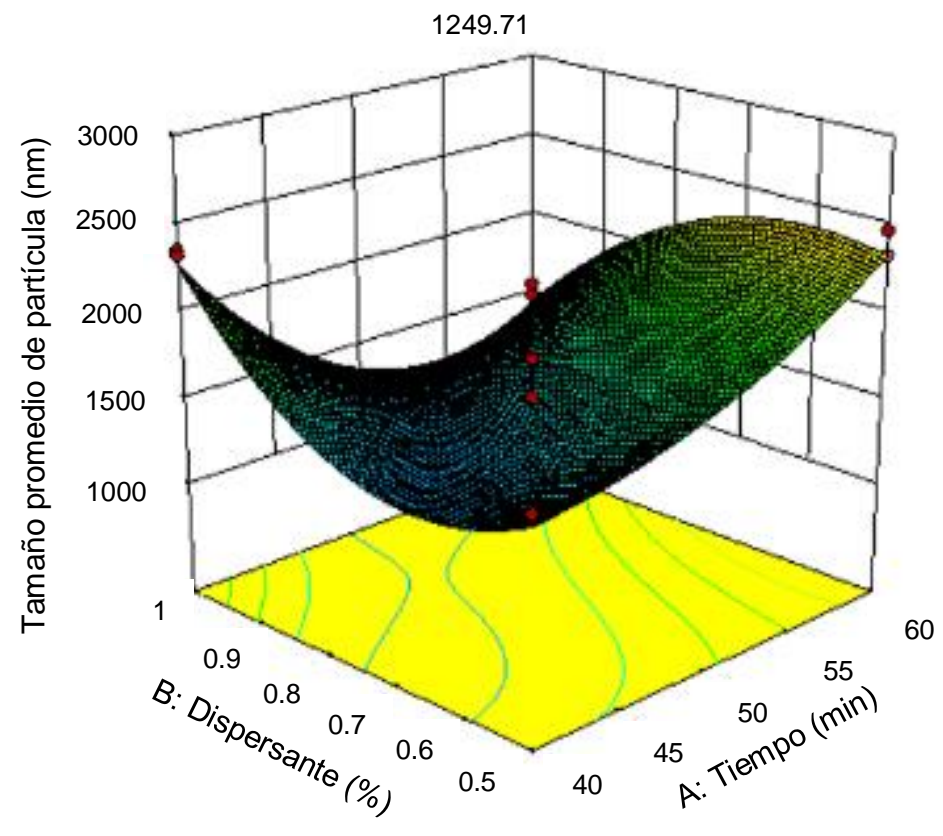

Fig. 1: Superficie de respuesta para tamaño de partícula en el proceso de dispersión a alta cizalla 
En la figura 1 se muestra el comportamiento gráfico de la respuesta (TP) en función de los factores. Para la variable PDI no hubo un modelo significativo que permitiera explicarlo en función de los factores evaluados, por lo cual no se tuvo en cuenta en la optimización del modelo. El polinomio que entrega el ANOVA describe la influencia de las variables sobre el TP como se indica en la Ecuación 1.

$$
\begin{aligned}
& T P=+1497.20+(412.95 * A)-(229.46 * B)-(401.62 * A B)+\left(337.43 * A^{2}\right)+\left(63.68 * B^{2}\right)+\left(188.83 * A^{2} B\right)- \\
& \left(426.08 * A B^{2}\right)
\end{aligned}
$$

\section{Optimización del modelo}

El modelo de la ecuación 1, fue optimizado para predecir el valor de los factores que minimicen el tamaño de partícula $(\mathrm{nm})$, la solución numérica se muestra en la tabla 4. Así mismo se realizaron ensayos adicionales (valores experimentales) para validar los valores predichos.

Tabla 4: Optimización numérica dispersión alta cizalla

\begin{tabular}{|c|c|c|c|c|c|}
\hline & Tiempo $(\mathrm{min})$ & \% Dispersante & TP $(\mathrm{nm})$ & PDI & Deseabilidad \\
\hline Valores Predichos & 53.94 & 1.00 & 1249.71 & 0.53 & 0.90 \\
\hline Valores Experimentales & 53.94 & 1.00 & 1348.23 & 0.58 & 0.90 \\
\hline
\end{tabular}

Efecto del solvente y la amplitud de la onda de ultrasonido sobre el TP de NPs de $\mathrm{CaCO}_{3}$

Los resultados del ANOVA para la variable tamaño de partícula (TP) en la obtención de NPs mediante ultrasonido de alta intensidad se indican en la tabla 5, donde se evidencia la significancia estadística del modelo, el valor-P de cada factor o interacción, el $R^{2}, R^{2}$-Ajustado y la carencia de ajuste.

Tabla 5: Análisis de varianza TP

\begin{tabular}{|l|c|}
\hline \multicolumn{1}{|c|}{ Fuente (Xi) } & Valor -P \\
\hline Modelo & 0.0007 \\
\hline A-Solvente & 0.0019 \\
\hline $\mathrm{B}$-Amplitud & 0.0136 \\
\hline $\mathrm{AB}$ & 0.0511 \\
\hline $\mathrm{A}^{2}$ & 0.0021 \\
\hline $\mathrm{B}^{2}$ & 0.5185 \\
\hline $\mathrm{A}^{2} \mathrm{~B}$ & 0.0164 \\
\hline $\mathrm{AB}^{2}$ & 0.0101 \\
\hline Carencia de Ajuste & 0.2048 \\
\hline $\mathrm{R}^{2}$ & 0.9784 \\
\hline $\mathrm{R}^{2}$-Ajustado & 0.9482 \\
\hline
\end{tabular}

El análisis de varianza arrojó un modelo cúbico, con una carencia de ajuste no significativa y un $\mathrm{R}^{2}$ de 0.9784 . La variable con mayor significancia fue el solvente, indicando que éste tiene un mayor efecto sobre el tamaño de partícula (TP). Este efecto posiblemente está asociado a un aumento en la presión de vapor del solvente, que a su vez hace que disminuya la tensión superficial y la viscosidad del medio acuoso, favoreciendo que la generación de burbujas aumente la cavitación y como consecuencia se obtenga una mayor disminución del tamaño de las partículas de carbonato de calcio. Por su parte la amplitud también tiene efecto significativo sobre TP, dado que la cantidad de energía que puede transmitir una sonda ultrasónica a través de la punta del sonotrodo para lograr la cavitación depende de la amplitud utilizada y la potencia de sonicación. A niveles de potencia más altos, el número de eventos de cavitación aumenta puesto que se forma un mayor número de burbujas de cavitación transitorias, lo que contribuye a la magnitud de la rotura de partículas para la fragmentación del $\mathrm{CaCO}_{3}$ (Jordens et al., 2016).

El polinomio que entrega el ANOVA describe la influencia de las variables sobre el tamaño promedio de partícula (TP) (Ecuación 2). En el se observa que el efecto de la sonicación sobre el tamaño de partícula de $\mathrm{CaCO}_{3}$, depende de manera conjunta tanto de la amplitud como del \% de solvente, factores que presentan efecto tanto en su término independiente como en algunos cuadráticos, e interacciones de tercer orden (tabla 3). Por su parte, en la figura 2 se muestra el comportamiento gráfico de la respuesta (TP) en función de los factores.

$T P=+844.76+\left(106.07^{\star} A\right)+\left(66.47^{\star} B\right)+\left(45.50^{\star} A B\right)-\left(78.38^{\star} A^{2}\right)-\left(9.38^{\star} B^{2}\right)-\left(89.47^{\star} A^{2} B\right)+\left(101.43^{\star} A B^{2}\right)$ 


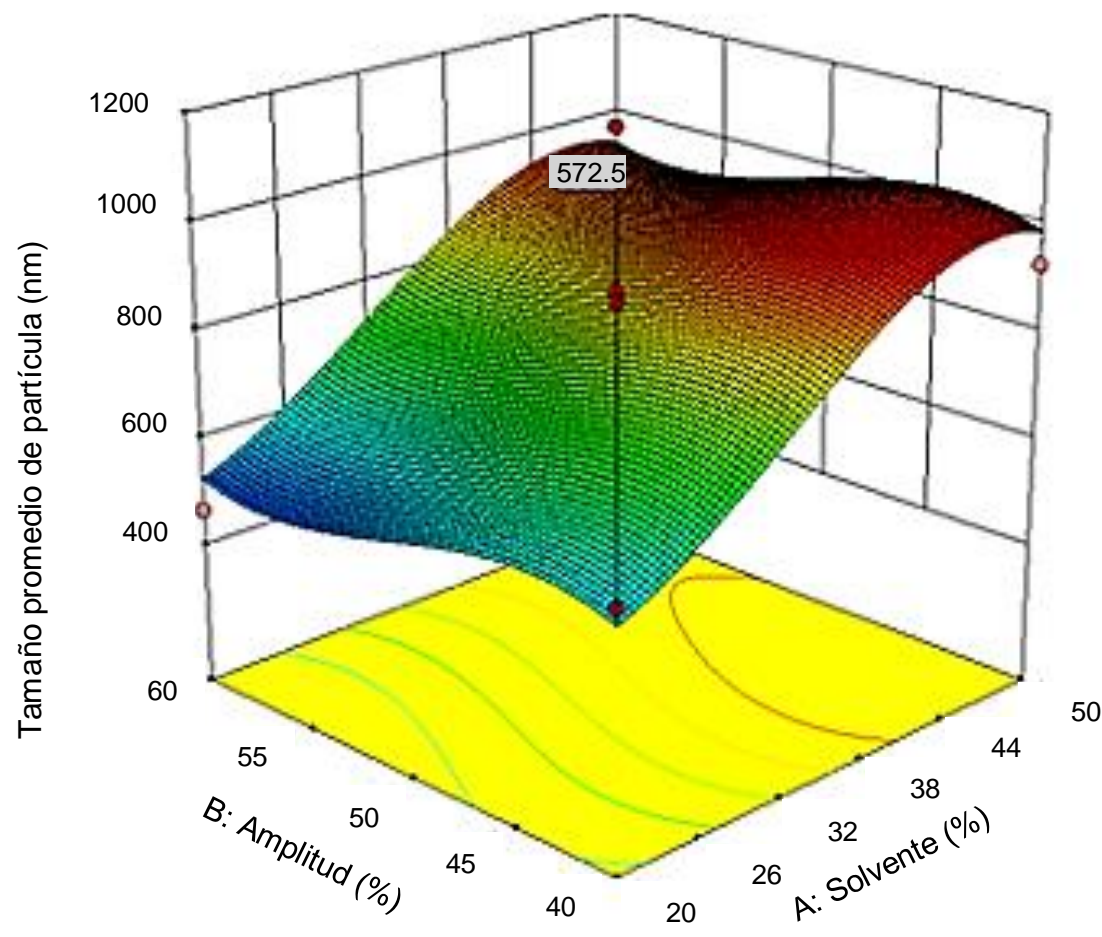

Fig. 2: Superficie de respuesta para tamaño de partícula en el proceso de ultrasonido de alta intensidad

EI ANOVA para IPD indica un modelo significativo, con una carencia de ajuste no significativa; se ajustó a un modelo cúbico donde la interacción con mayor significancia fue $A^{2}$. El polinomio que entrega el ANOVA describe la influencia de las variables sobre el IPD (Ecuación 3). En la figura 3 se muestra el comportamiento gráfico de la respuesta (IPD) en función de los factores.

$I P D=+0.51-\left(0.021^{*} A\right)-\left(0.088^{*} B\right)-(0.12 * A B)+\left(0.20 * A^{2}\right)+\left(0.030^{*} B^{2}\right)+\left(0.21^{*} A^{2} B\right)$

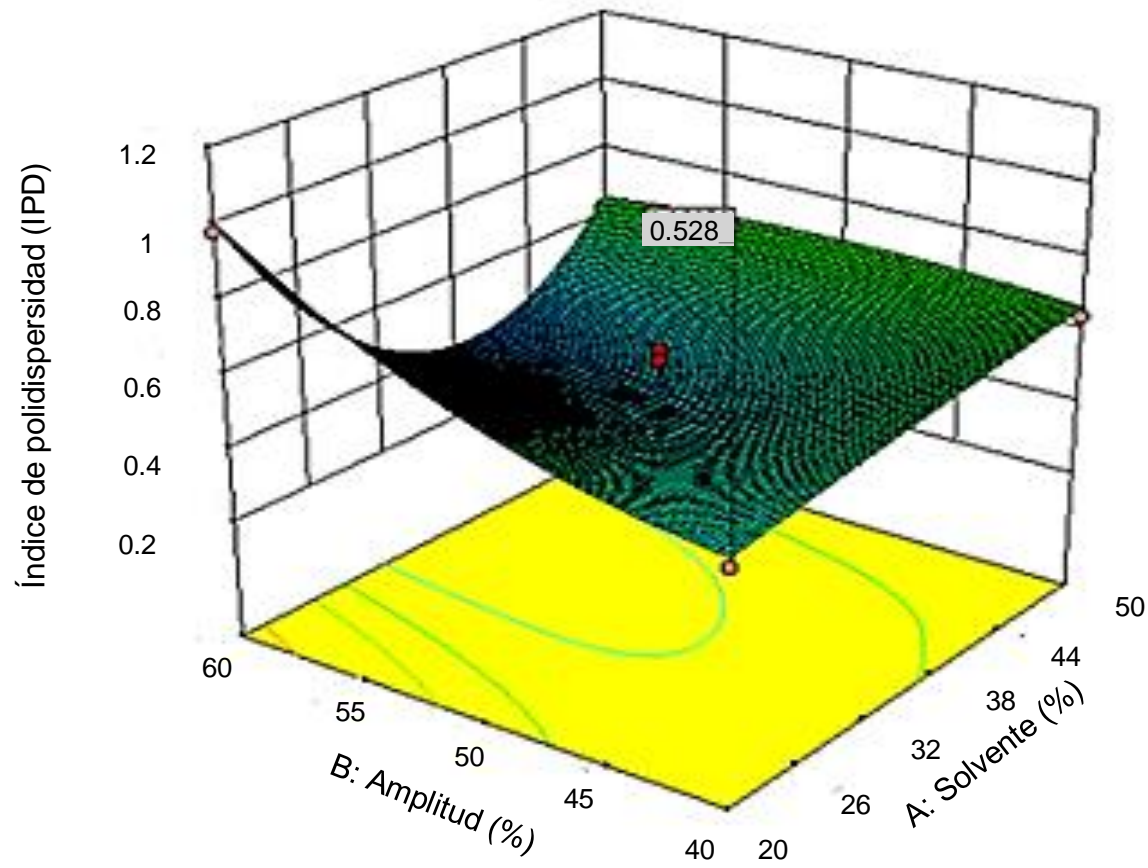

Fig. 3: Superficie de respuesta para PDI en el proceso de ultrasonido de alta intensidad 


\section{Optimización del modelo}

El modelo de la ecuación 2 correspondiente a TP y la ecuación 3 para IPD fue optimizado para predecir el valor de los factores que minimice el tamaño de partícula $(\mathrm{nm})$ y el IPD mediante aplicación de ultrasonido, la solución numérica se muestra en la tabla 6 , así mismo se validó de forma experimental. Para la variable PZ no hubo un modelo significativo que permitiera explicarlo en función de los factores evaluados, por lo cual no se tuvo en cuenta en la optimización del modelo.

Tabla 6: Optimización numérica para ultrasonido de alta intensidad

\begin{tabular}{|c|c|c|c|c|c|c|}
\hline & \% Solvente & $\%$ Amplitud & TP $^{*}(\mathrm{~nm})$ & IPD & PZ $(\mathrm{mV})$ & Deseabilidad \\
\hline Valores Predichos & 20 & 40 & 572.5 & 0.52 & -14.9 & 0.90 \\
\hline Valores Experimentales & 20 & 40 & 536.7 & 0.60 & -13.2 & 0.90 \\
\hline
\end{tabular}

\section{Caracterización de NPs de carbonato de calcio}

A las nanopartículas de carbonato de calcio obtenidas de la cáscara de huevo, bajo las condiciones óptimas mediante el proceso combinado de dispersión de alta cizalla y ultrasonido de alta intensidad, se les realizó la siguiente caracterización:

\section{Tamaño de partícula, polidispersidad y potencial zeta}

Se realizó análisis de TP, IPD y $\mathrm{PZ}$ a las $\mathrm{NPs} \mathrm{CaCO}_{3}$ obtenidas a partir del proceso de sonofragmentación de cáscara de huevo realizada en el laboratorio después de $2 \mathrm{~h}$ de proceso en bache y se comparó con el escalado realizado en el equipo industrial ultrasonido de alta intensidad durante el mismo tiempo. En la tabla 7 , se aprecia que a través de la sonofragmentación realizada en el laboratorio se obtiene un tamaño promedio de partícula cercano al reportado por Oehlke et al., (2014) $(550 \mathrm{~nm})$, mientras que en el escalado del proceso se obtuvieron mejores resultados tanto en el TP como el IPD los cuales resultaron menores; lo que demostró que la fragmentación de partículas mediante ultrasonido de alta intensidad resulta favorecido por la formación de burbujas de cavitación transitorias que con potencias más altas conducen a partículas más pequeñas como lo indicaron Jordens et al., (2016). Esto se debe a que las altas potencias crean grandes burbujas de cavitación que implosionan violentamente y por lo tanto generan fuertes ondas de choque, microjets y turbulencias que eventualmente crean ruptura de las partículas cercanas.

Este mecanismo de ruptura para la reducción de tamaño de partícula se puede caracterizar como fractura o abrasión (Mosquera-Vivas et al., 2019). El primero (fractura), consiste en la división de la partícula original en partículas más pequeñas de tamaño variable dando como resultado una amplia distribución del tamaño de partícula; mientras que la abrasión, en contraste, es un mecanismo de reducción de tamaño en el que las partículas significativamente más pequeñas se desprenden de los bordes y las superficies de las partículas originales. En tanto, estos mecanismos explican la amplia distribución que se presenta en el tamaño de partícula obtenidas de la cáscara de huevo en la sonofragmentación. Esto corresponde a efectos mecánicos, que surgen de las fuerzas de cizalladura durante la fragmentación ultrasónica; los cuales producen cambios físicos en estas partículas sólidas. Este efecto de la sonofragmentación puede estar relacionado con la interacción partícula-onda de choque (Benavides-Guerrero et al., 2020). Adicionalmente, la amplia distribución de tamaño también puede deberse a la alta variabilidad de tamaño en la microsuspensión utilizada como insumo en el proceso de sonofragmentación.

Tabla 7: Características de tamaño, IPD y potencial zeta de nanopartículas $\mathrm{CaCO}_{3}$ en cada proceso

\begin{tabular}{|c|c|c|c|}
\hline Proceso $(120 \mathrm{~min})$ & TP $(\mathrm{nm})$ & IPD & PZ $(\mathrm{mV})$ \\
\hline Laboratorio & $572.51 \pm 93.46$ & $0.54 \pm 0.04$ & $-14.9 \pm 3.92$ \\
\hline Escalado & $281.34 \pm 25.83$ & $0.51 \pm 0.05$ & $-22.4 \pm 3.47$ \\
\hline
\end{tabular}

El potencial zeta es un parámetro importante que puede ayudar a predecir la estabilidad electrostática de los sistemas coloidales y está relacionado con la carga eléctrica de la superficie de la partícula, por tanto, este parámetro permitió predecir la estabilidad de almacenamiento de las dispersiones coloidales submicrométricas (Huang et al., 2020). Los valores promedio de $\mathrm{PZ}$ observados en las partículas $\mathrm{CaCO}_{3}$ obtenidas mediante la aplicación de ultrasonido en el laboratorio $(-14.9 \pm 3.92 \mathrm{mV})$ y en el escalado $(-22.4 \pm$ $3.47 \mathrm{mV}$ ) confirmaron que la mayor estabilidad de las partículas obtenidas en el proceso de escalado se pueden atribuir a una mayor carga negativa de las partículas, que les permite repelerse entre sí con mayor intensidad permitiendo durante más tiempo que las partículas permanezcan en suspensión de forma individualizada y esto sumado a un menor TP obtenido $(281.34 \pm 25.83 \mathrm{~nm})$ que también favorece la estabilidad del sistema, lo cual puede estar relacionado con que la suspensión tratada con mayor intensidad de ultrasonido, formó una suspensión más estable, fina y homogénea de nanopartículas de $\mathrm{CaCO}_{3}$ (Shirsath et al., 2017). 


\section{Microscopías electrónicas}

Las imágenes de microscopia electrónica de barrido SEM y composición química elemental de las partículas obtenidas de la cáscara de huevo tras la sonofragmentación, se ilustran en la figura 4 y 5 . Estas imágenes revelaron la morfología superficial, el tamaño y la forma de las nanopartículas derivadas de la cáscara de huevo, las cuales mostraron ser de apariencia rugosa, de forma irregular con un tamaño que varió desde 45 $\mathrm{nm}$ a $550 \mathrm{~nm}$, este último se debe a la aglomeración de partículas, lo que conduce a resultados de medición más grandes en cuanto a la distribución de tamaño de partícula, hallazgo similar al de Mijan et al., (2014) y Huang et al., (2009) quienes indicaron la aglomeración de nanocarbonato cálcico y nano citrato cálcico en su estudio. Estos resultados mostraron que las $\mathrm{NPs}$ de $\mathrm{CaCO}_{3}$ no son homogéneas, por lo que varias partículas primarias tienden a agruparse formando aglomerados. La micrografía de la Fig. 4, se puede correlacionar con el alto IPD obtenido por DLS. Esta tendencia a la aglomeración es inducida por las fuerzas de Van-der-Waals que actúan entre las partículas individuales, generando alta tensión superficial (Salman et al., 2020), y a pesar de que la vibración ultrasónica lograba desaglomerar, las partículas se volvían a unir rápidamente formando agregados, situación que coincide con lo que observaron Zhang et al., (2004) en su investigación con NPs de $\mathrm{CaCO}_{3}$.

La composición química elemental del nanopolvo obtenido de la cáscara de huevo, se analizó cualitativamente mediante espectros EDS, los cuales mostraron picos distintivos correspondientes a las partículas de cáscara de huevo. Como se muestra en la figura 5, se identificaron picos de carbono (C), oxígeno (O) y calcio (Ca) en los espectros de las $\mathrm{NPs}_{\mathrm{CaCO}}$, lo que confirmó la pureza de las cáscaras de huevo e indicó que están compuestas exclusivamente de C, Ca y O y una pequeña traza de Mg (Nasrollahzadeh et al., 2016). La proporción de $\mathrm{Ca}$ obtenida por EDS en las nanopartículas de $\mathrm{CaCO}_{3}$ coincide con la cantidad de $\mathrm{Ca}$ obtenido en la caracterización inicial de este material $(33.9 \%$ de $\mathrm{Ca})$, indicando pocas pérdidas de este elemento y alta estabilidad química, de forma similar Ray et al., (2017), reportaron un 34.1\% de Ca a partir de cáscara de huevo.

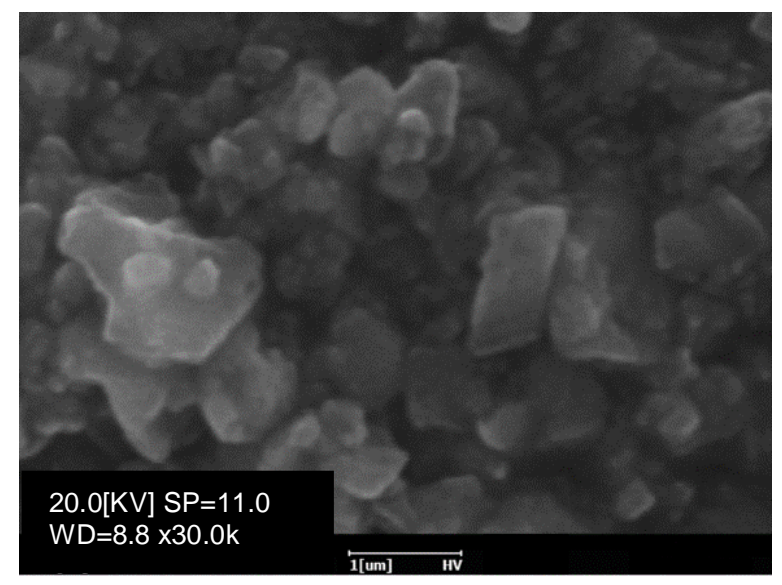

Fig. 4: Micrografía electrónica de barrido de nanopolvo de cáscara de huevo

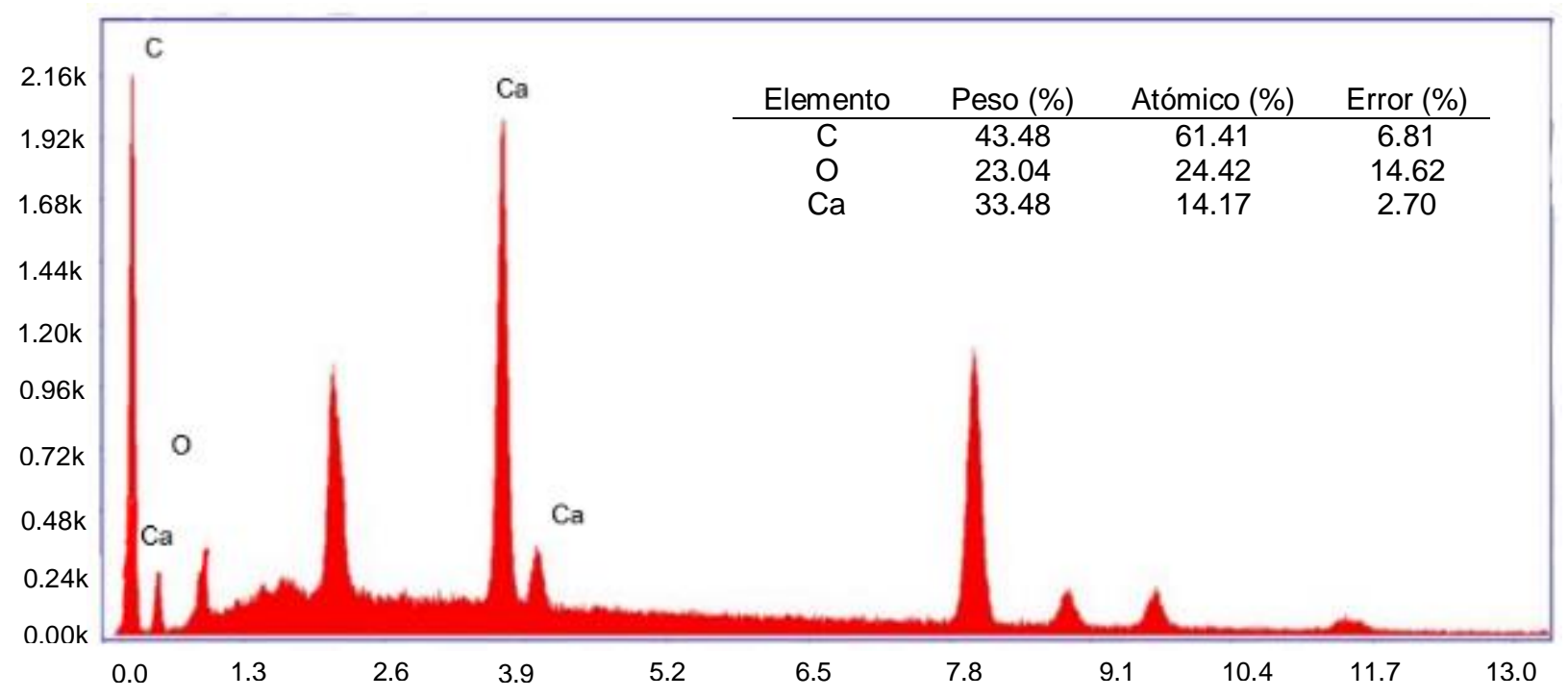

Fig. 5: Composición química elemental de nanopolvo de cáscara de huevo SEM-EDS 
Las micrografías obtenidas mediante microscopía electrónica de transmisión (TEM) permitieron observar en diferentes aumentos que las muestras de nanopartículas de $\mathrm{CaCO}_{3}$ obtenidas a partir de la cáscara de huevo, están conformadas por partículas cristalinas de forma irregular y naturaleza porosa como se puede apreciar en la Fig. 6. Los poros identificados al interior de las nanopartículas pueden variar entre 1,86 nm a 3,04 nm aproximadamente, esto nos confirma una de las características que hace que las cáscaras de huevo tengan aplicación como soportes/catalizadores eficientes con propiedades económicas y respetuosas con el medio ambiente, donde se utiliza como una plantilla dura y eficaz gracias a su estructura porosa (Li et al., 2020).

Los cristales observados en las micrografías de la Fig. 7 se encuentran en un rango aproximado de $10 \mathrm{~nm}$ a $60 \mathrm{~nm}$, los cuales revelan la característica cristalina de las NPs derivadas de la cáscara de huevo, esto se confirmó con los patrones de difracción de electrones del área seleccionada (Fig. 8), mostrándose como una imagen de anillo de varios círculos que indica la naturaleza policristalina de las nanopartículas de $\mathrm{CaCO}_{3} . \mathrm{A}$ partir de estos cristales se forman estructuras de mayor tamaño logrando alcanzar un diámetro de hasta 500 $\mathrm{nm}$ en promedio, lo cual corrobora que las partículas presentan una tendencia a la aglomeración como se evidenció en la Fig. 4.

Por otra parte, la microscopía de fuerza atómica (AFM) ofrece un perfil 3D de la superficie de la partícula, que permitió evidenciar que el polvo de cáscara de huevo a escala nano se caracteriza por su estructura rugosa e irregular como puede apreciarse en la topografía de la figura 7. Los resultados para la topografía de los cristales obtenidos mostraron un espesor de $65.4 \mathrm{~nm}$ el cual es similar a lo encontrado por Polat y Sayan (2020) con un espesor de $54.36 \mathrm{~nm}$ a partir de $\mathrm{CaCO}_{3}$ obtenido mediante síntesis química.

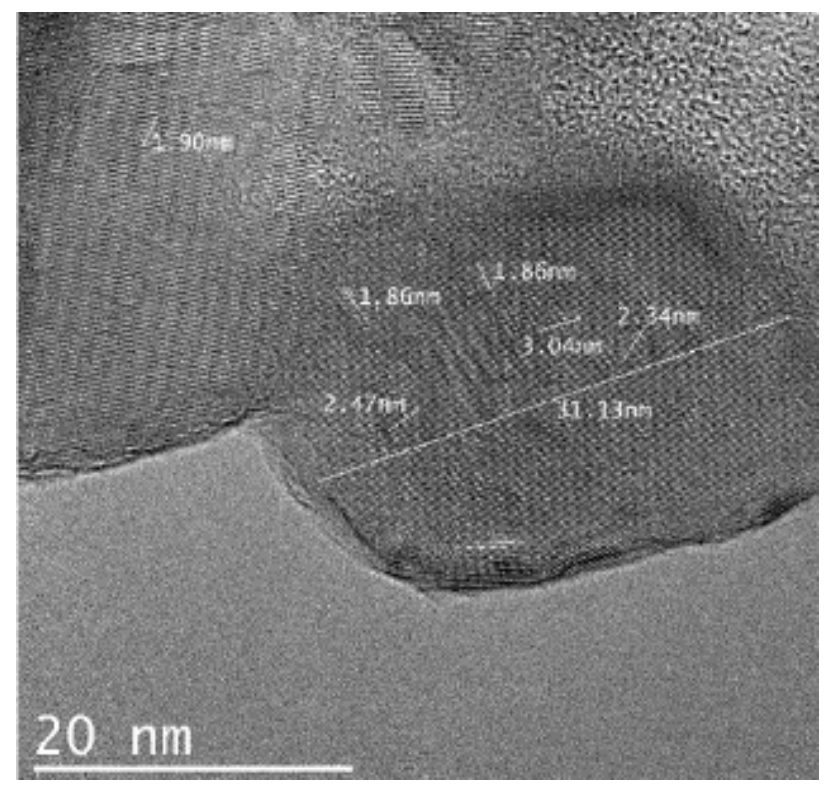

Fig. 6: Naturaleza porosa de $\mathrm{CaCO}_{3}$ obtenido de cáscara de huevo. Total magnificación: 450.00kx

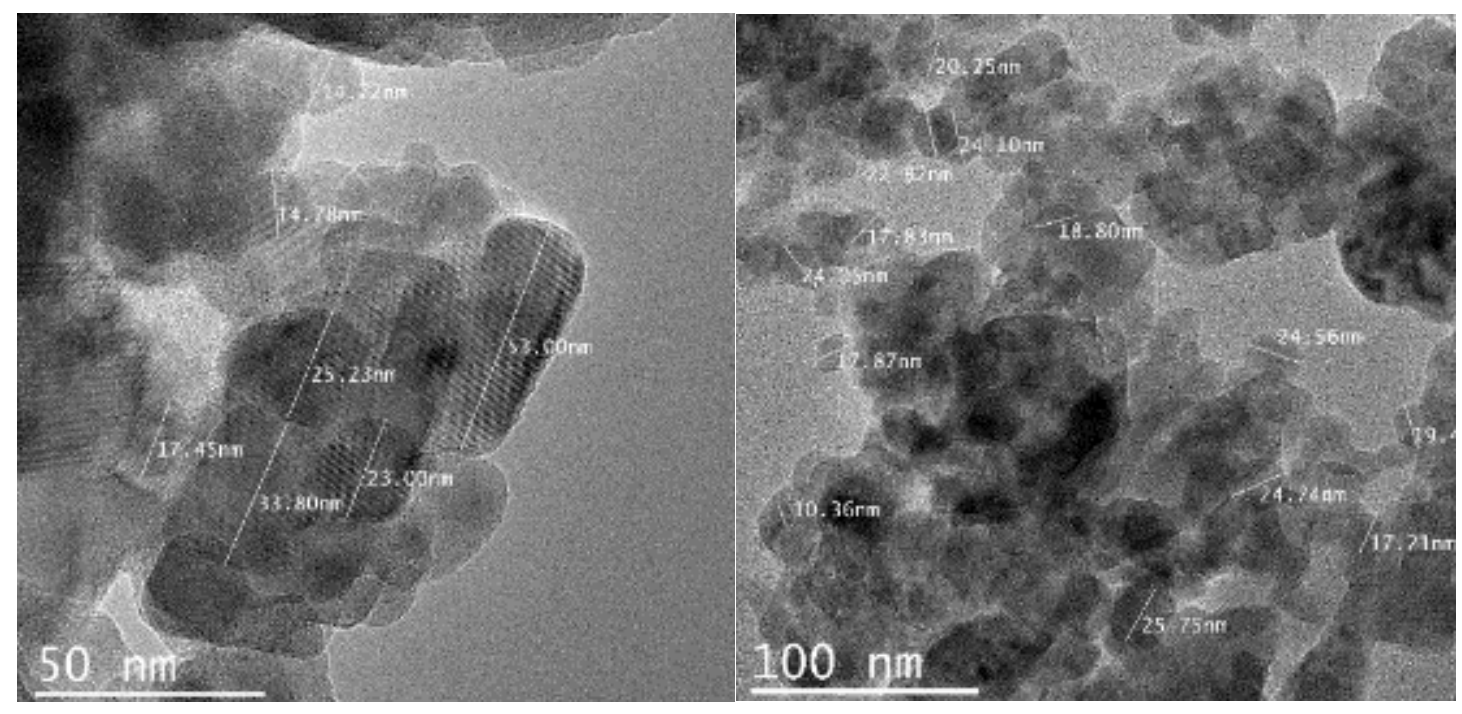

Fig. 7: Micrografías electrónicas de transmisión de cristales de $\mathrm{CaCO}_{3}$ obtenidos de nanopolvo de cáscara de huevo. Total magnificación: $145.00 \mathrm{kx}$ 


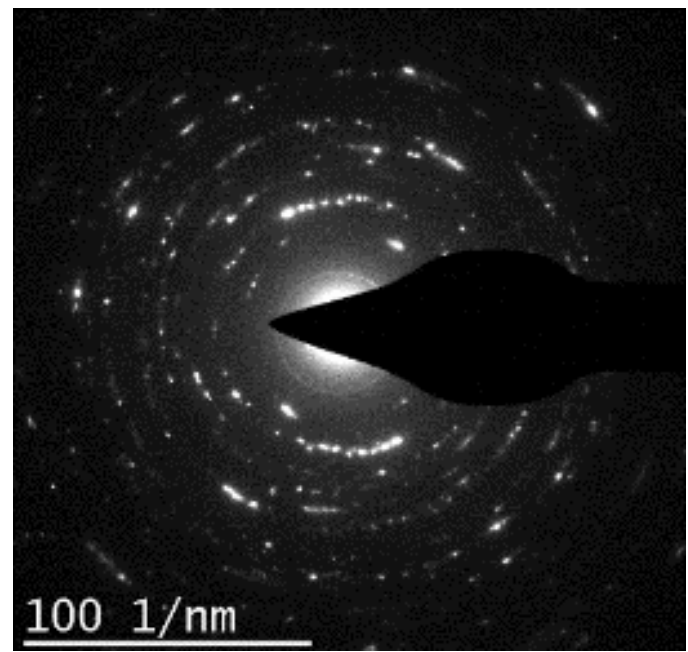

Fig. 8: Patrón de difracción de electrones. Total magnificación: 0.49 kx
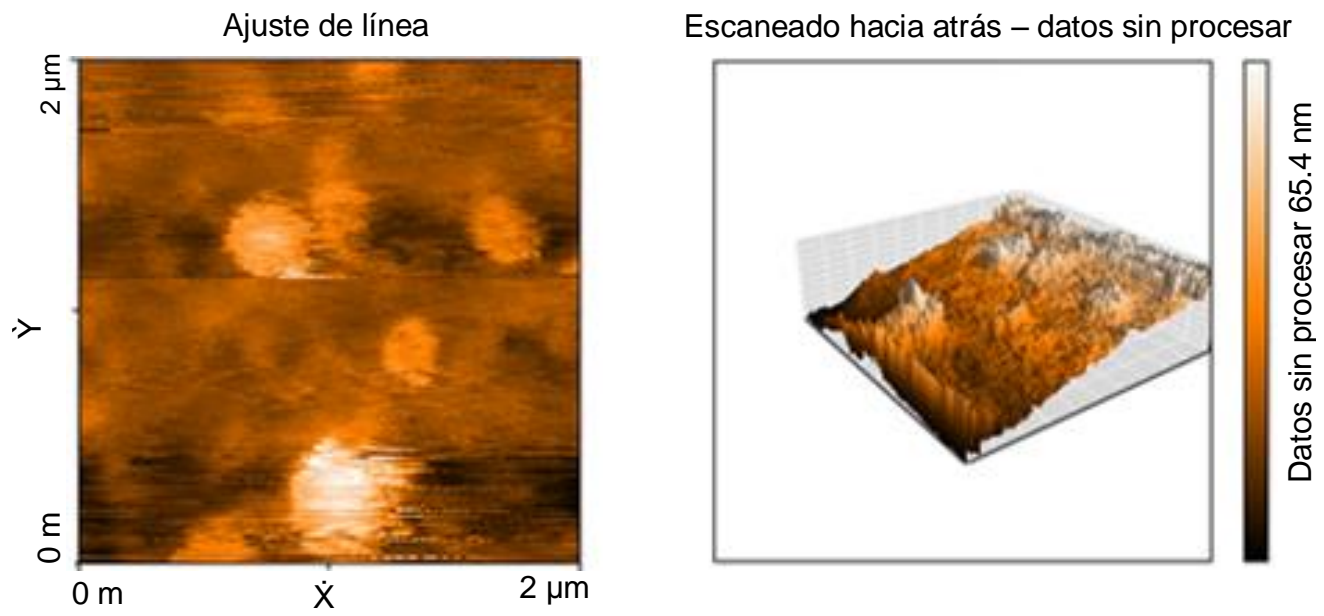

Fig. 9: Topografía AFM de nanopartículas $\mathrm{CaCO}_{3}$ obtenidas de cáscara de huevo

\section{Difracción de rayos $X$}

La figura 8 muestra el difractograma del carbonato de calcio obtenido de la cáscara de huevo. Las $\mathrm{NPs} \mathrm{CaCO}_{3}$ se caracterizaron por picos amplios sin fases secundarias, lo que indica la pureza de las partículas; adicionalmente, se pudo inferir que el proceso de dispersión y sonofragmentación no generó ningún cambio de fase en la cáscara del huevo (Jeong et al., 2013). Este resultado indicó que las nanopartículas de cáscara de huevo se pueden obtener con su pureza y cristalinidad inherentes (Mijan et al., 2014). Entre estos planos se observó el pico más agudo que es el plano característico del $\mathrm{CaCO}_{3}$ romboédrico y reveló la alta cristalinidad de la muestra, cuya fase principal es la calcita con un contenido de $98.7 \%$ como se indicó en la tabla 8. Este resultado coincide con el reportado por Ramasamy et al., (2018) en su estudio de nanocarbonato de calcio obtenido de piedra caliza.

Tabla 8: DRX de nanopartículas de $\mathrm{CaCO}_{3}$ de cáscara de huevo

\begin{tabular}{|c|c|c|}
\hline Fase & Fases Cristalinas & Composición (\%) \\
\hline Calcita & $\mathrm{C}_{1} \mathrm{Ca}_{1} \mathrm{O}_{3}$ & 98.7 \\
\hline Quarzo Bajo & $\mathrm{O}_{2} \mathrm{Si}_{1}$ & 1.3 \\
\hline
\end{tabular}

\section{Área de superficie específica}

El área de superficie específica de $\mathrm{NPs}_{\text {de }} \mathrm{CaCO}_{3}$ medida por el método $\mathrm{N}_{2}$ Brunauere Emmette Teller fue $11.13 \mathrm{~m}^{2} / \mathrm{g}$, un valor muy cercano al reportado por Huang et al., (2020) y Polat y Sayan (2020) de $11.20 \mathrm{~m}^{2} / \mathrm{g}$ alcanzado en la síntesis de nanocarbonato cálcico mediada por ultrasonidos de alta intensidad. El área de superficie específica real fue más pequeña de lo esperado, porque las partículas primarias de calcio se 
aglomeraron para formar grupos más grandes. Sin embargo, se pudo comprobar que el proceso de dispersión de alta cizalla y ultrasonido condujo a un aumento en el área de superficie específica $\mathrm{BET}$ de $\mathrm{CaCO}_{3}$.

La obtención de nanopartículas de carbonato de calcio derivadas de cáscara de huevo de gallina mediante métodos combinados, muestra la posibilidad de escalar la producción de este material para el aprovechamiento de un residuo subvalorado y al mismo tiempo revela la oportunidad de explorar diversas áreas en la industria alimentaria, como la formulación de alimentos con ingredientes nano ( $\left.\mathrm{NPs} \mathrm{CaCO}_{3}\right)$ para mejorar el valor nutricional y favorecer la bioaccesibilidad y biodisponibilidad del calcio a través de sistemas nanoestructurados, que terminen siendo potenciales promotores de la salud mediante el desarrollo de alimentos funcionales o nutraceúticos a partir de estas nanopartículas, con el fin de dar respuesta a las distintas necesidades de calcio en el organismo humano. A partir de los métodos empleados en esta investigación se logró demostrar un mayor rendimiento del nano polvo, en un tiempo más corto, sin el uso de solventes y contaminantes químicos, a diferencia de las metodologías hasta ahora empleadas para la obtención de NPs a partir de cáscara de huevo con enfoque Top Down, como la molienda húmeda en molinos de alta energía; por lo que resulta interesante escalar en ultrasonido de alta intensidad, donde los parámetros industriales son fáciles de operar, con alta capacidad de producción continua, sin aplicación de disolventes orgánicos, constituyendo este método como una tecnología amigable con el ambiente.

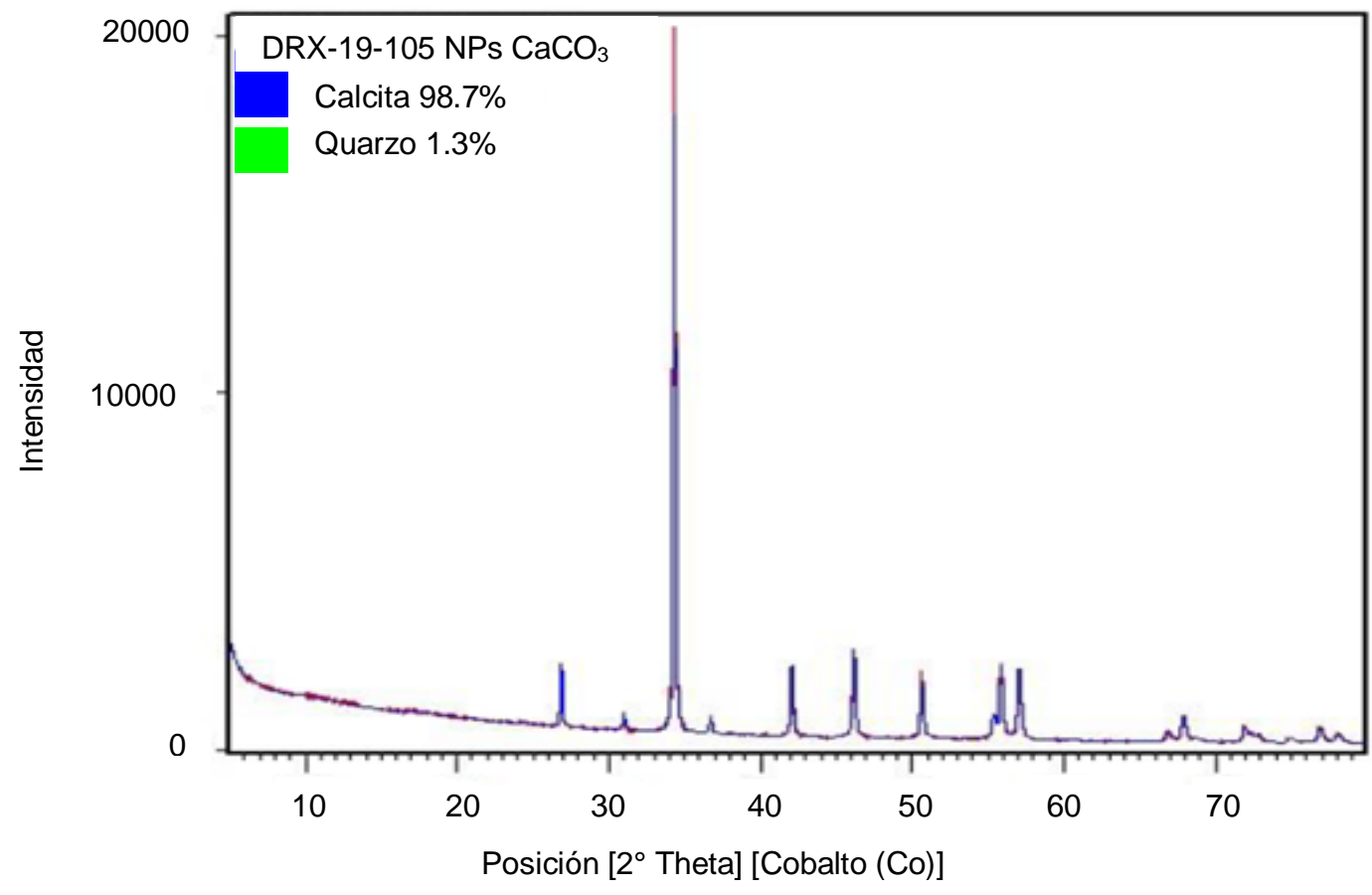

Fig. 10: Difractograma de nanopartículas de $\mathrm{CaCO}_{3}$

\section{CONCLUSIONES}

De acuerdo a los resultados obtenidos y analizados en esta investigación, se pueden extraer las siguientes conclusiones sobre el efecto de métodos combinados para transformar la cáscara de huevo en NPs de $\mathrm{CaCO}_{3}:$ 1) La dispersión a alta cizalla es un mecanismo más efectivo que la molienda de bolas empleado actualmente para reducir el tamaño de partícula de $\mathrm{CaCO}_{3}$;2) La aplicación de ultrasonido de alta intensidad permitió obtener NPs de $\mathrm{CaCO}_{3}$ y es un mecanismo escalable a nivel industrial para agregar valor a las cáscaras de huevo; 3) La combinación de los métodos mencionados en este estudio y la caracterización mediante microscopia, BET y XRD nos confirman que se puede obtener $\mathrm{NPs}$ de $\mathrm{CaCO}_{3}$ con unas características fisicoquímicas similares a las conseguidas través de métodos como la molienda húmeda de alta energía; disminuyendo el número de pruebas y el tiempo de proceso, ya que estos últimos se pueden tomar hasta 25 horas.

\section{AGRADECIMIENTOS}

Los autores de este trabajo agradecen a la Universidad de Antioquia y a MINCIENCIAS (convocatoria No 727 de 2015) por el apoyo financiero en la ejecución del proyecto mediante el programa de Doctorados Nacionales en Colombia. 


\title{
NOTACION
}

\author{
NPs $=$ Nanopartículas \\ $\mathrm{CaCO}_{3}=$ Carbonato de calcio \\ $\mathrm{TP}=$ Tamaño promedio de partícula \\ $\mathrm{IPD}=$ Índice de polidispersidad \\ $\mathrm{PZ}=$ Potencial zeta \\ SEM= Microscopía electrónica de barrido \\ TEM= Microscopía electrónica de transmisión \\ AFM= Microscopía de fuerza atómica \\ $\mathrm{XRD}=$ Difracción de rayos $\mathrm{X}$ \\ $\mathrm{BET}=$ Brunauer, Emmett y Teller \\ $\mathrm{FAO}=$ Food and Agriculture Organization \\ $\mathrm{ENM}=$ Nanomateriales \\ $A O A C=$ Association of Official Analytical Chemists \\ $\mathrm{AD}=$ Agua destilada \\ $\mathrm{AD} / \mathrm{AC}=$ Agua destilada y ácido acético al $5 \%$ \\ $\mathrm{AD} / 80^{\circ} \mathrm{C}=$ Agua destilada a $80^{\circ} \mathrm{C}$ \\ DLS= Dispersión dinámica de luz \\ EDS= Dispersión de energía rayos $\mathrm{X}$
}

\section{REFERENCIAS}

Arabhosseini, A., Application of Eggshell Wastes as Valuable and Utilizable Products: A Review, https://doi.org/10.17221/6/2017-RAE, Res. Agric. Eng, 64(2), 104-114 (2018)

Baláž, M., Ball Milling of Eggshell Waste as a Green and Sustainable Approach: A Review, https://doi.org/10.1016/j.cis.2018.04.001, Colloid Interface Sci., 256, 256-275 (2018)

Benavides-Guerrero, R., Revelo-Cuarán, Y. A., y otros dos autores, Extracción Asistida con Ultrasonido de Compuestos Fenólicos de dos Variedades de Papas (Solanum phureja) Nativas Andinas y Evaluación de su Actividad Antioxidante, https://dx.doi.org/10.4067/S0718-07642020000500043, Inf. Tecnol., 31(5), 43-50 (2020)

De Angelis, G., Medeghini, L., y otros dos autores, Recycling of Eggshell Waste into Low-cost Adsorbent for Ni Removal from Wastewater, https://doi.org/10.1016/j.jclepro.2017.07.085, J. Clean Prod., 164, 1497-1506 (2017)

Ding, Q., Kang, Z., y otros cuatro autores, Conversion of Waste Eggshell into Difunctional Au/CaCO3 Nanocomposite for 4-Nitrophenol Electrochemical Detection and Catalytic Reduction, https://doi.org/10.1016/j.apsusc.2020.145526, Appl. Surf. Sci., 510, 145526 (2020)

Erfanian, A., Mirhosseini, H., y otros tres autores, Influence of Nano-size Reduction on Absorption and Bioavailability of Calcium from Fortified Milk Powder in Rats, https://doi.org/10.1016/j.foodres.2014.08.026, Int. Food Res. J., 66, 1-11 (2014)

Hassan, T.A., Rangari, V.K., y otros dos autores, Sonochemical Effect on Size Reduction of CaCO3 Nanoparticles Derived from Waste Eggshells, https://doi.org/10.1016/j.ultsonch.2013.01.016, Ultrason. Sonochem., 20(5), 1308-1315 (2013)

Hess, B.J., Kolar, P., y otros tres autores, Evaluation of Waste Eggshells for Adsorption of Copper from Synthetic and Swine Wastewater, https://doi.org/10.13031/trans.12599, Trans. ASABE, 61(3), 967-976 (2018)

Huang, S., Chen, J.C., y otros dos autores, Effects of Nano Calcium Carbonate and Nano Calcium Citrate on Toxicity in ICR Mice and on Bone Mineral Density in an Ovariectomized Mice Model, https://doi.org/10.1088/09574484/20/37/375102, Nanotechnology, 20(37), 375102 (2009)

Huang, X., Dong, K., y otros seis autores, Physicochemical and Structural Characteristics of Nano Eggshell Calcium Prepared by Wet Ball Milling, https://doi.org/10.1016/j.lwt.2020.109721, LWT, 131, 109721 (2020)

Jeong, M.S., Cho, H.S., y otros cinco autores, Physico-chemical Characterization-based Safety Evaluation of Nanocalcium, https://doi.org/10.1016/j.fct.2013.08.024, Food Chem. Toxicol., 62, 308-317 (2013)

Jeyakumar, N., Narayanasamy, B., y otros tres autores, Preparation, Characterization and Effect of Calcium Carbonate and Titanium Dioxide Nano Additives on Fuel Properties of Tire Oil Diesel Blend,

https://doi.org/10.1080/15567036.2018.1486919, Energ. Source Part A Journal, 40 (15), 1798-1806 (2018)

Jordens, J., Appermont, T., y otros tres autores, Sonofragmentation: Effect of Ultrasound Frequency and Power on Particle Breakage, https://doi.org/10.1021/acs.cgd.6b00088, Cryst. Growth Des., 16(11), 6167-6177 (2016)

Li, Z., Yang, D.P., y otros cinco autores, Waste Eggshells to Valuable $\mathrm{Co} 3 \mathrm{O} 4 / \mathrm{CaCO} 3$ Materials as Efficient Catalysts for VOCs Oxidation, https://doi.org/10.1016/j.mcat.2020.110766, Mol. Catal., 483, 110766 (2020) 
MacNeil, J., Method and Apparatus for Separating a Protein Membrane and Shell Material in Waste Egg Shells, US 6176376 B1, class 061, 28, 52, 23 de enero (2001)

Mijan, M.A., Kim, D.H., y Kwak, H.S., Physicochemical Properties of Nanopowdered Eggshell, https://doi.org/10.1111/ijfs.12451, Int. J. Food Sci., 49(7), 1751-1757 (2014)

Minić, D.M., Blagojević, V.A., y otros cuatro autores, Nanocrystal Growth in Thermally Treated Fe 75 Ni 2 Si 8 B 13 C 2 Amorphous Alloy, https://doi.org/10.1007/s11661-012-1161-1, Metall. Mater. Trans. A., 43(9), 3062-3069, (2012)

Mittal, A., Teotia, M., y otros dos autores, Applications of Eggshell and Eggshell Membrane as Adsorbents: A Review, https://doi.org/10.1016/j.molliq.2016.08.065, J. Mol. Liq., 223, 376-387 (2016)

Mosquera-Vivas, E.S., Ayala-Aponte, A.A., y Serna-Cock, L., Ultrasonido y Deshidratación Osmótica como Pretratamientos a la Liofilización de Melón (Cucumis melo L.), https://dx.doi.org/10.4067/S0718-07642019000300179, Inf. Tecnol., 30(3), 179-188 (2019)

Nasrollahzadeh, M., Sajadi, S.M., y Hatamifard, A., Waste Chicken Eggshell as a Natural Valuable Resource and Environmentally Benign Support for Biosynthesis of Catalytically Active Cu/eggshell, Fe3O4/eggshell and Cu/Fe3O4/eggshell Nanocomposites, https://doi.org/10.1016/j.apcatb.2016.02.042, Appl. Catal. B., 191, 209-227 (2016)

Oehlke, K., Adamiuk, M., y otros cinco autores, Potential Bioavailability Enhancement of Bioactive Compounds Using Food-grade Engineered Nanomaterials: A Review of the Existing Evidence, https://doi.org /10.1039 / C3FO60067J, Food Funct., 5(7), 1341-1359 (2014)

Pohshna, C., Mailapalli, D.R., y Laha, T., Synthesis of Nanofertilizers by Planetary Ball Milling, https://doi.org/10.1007/978-3-030-33281-5_3,_Sustain. Agric. Res., 40, 75-112 (2020)

Polat, S., y Sayan, P., Ultrasonic-assisted Eggshell Extract-mediated Polymorphic Transformation of Calcium Carbonate, https://doi.org/10.1016/j.ultsonch.2020.105093, Ultrason. Sonochem., 66, 105093 (2020)

Ramasamy, V., Anand, P., y Suresh, G., Synthesis and Characterization of Polymer-mediated CaCO3 Nanoparticles Using Limestone: a novel approach, https://doi.org/10.1016/j.apt.2017.12.023, Adv. Powder Technol., 29(3), 818-834 (2018)

Ray, S., Barman, A.K., y otros dos autores, Chicken Eggshell Powder as Dietary Calcium Source in Chocolate Cakes, Pharm. Innov., 6(9): 01-04, E-ISSN Number: 2277- 7695 (2017)

Salman, A.D., Tatjána, J., y otros cuatro autores, Improvement of Mechanical Properties of Oil Well Cement by Incorporate Nano-CaCO3 Prepared from Eggshell Waste, https://doi.org/10.1088/1757-899X/765/1/012006, Mater. Sci. Eng. C, 765(1), 012006 (2020)

Shirsath, S.R., Bhanvase, B.A., y otros tres autores, A Novel Approach for Continuous Synthesis of Calcium Carbonate Using Sequential Operation of Two Sonochemical Reactors, https://doi.org/10.1016/j.ultsonch.2016.09.009, Ultrason. Sonochem., 35, 124-133 (2017)

Strobel, A., Romeis, S., y otros cuatro autores, Characterization of Stressing Conditions in Mills-A Comprehensive Research Strategy Based on Well-characterized Model Particles, https://doi.org/10.1016/j.powtec.2016.10.048, Powder Technol., 305, 652-661 (2017)

Waheed, M., Butt, M.S., y otros cinco autores, Eggshell Calcium: A Cheap Alternative to Expensive Supplements, https://doi.org/10.1016/j.tifs.2019.07.021, Trends Food Sci. Technol., 91, 219-230 (2019)

Zhang, Q.X., Yu, Z.Z., y otros dos autores, Crystallization and Impact Energy of Polypropylene/CaCO3 Nanocomposites with Nonionic Modifier, https://doi.org/10.1016/j.polymer.2004.06.044, Polymer, 45(17), 5985-5994 (2004) 
